\title{
Fetal Central Nervous System Anomalies Detected by Magnetic Resonance Imaging: A Two-Year Experience
}

\author{
Sepideh Sefidbakht, ${ }^{1}$ Sakineh Dehghani, ${ }^{1,}$ Maryam Safari, ${ }^{1}$ Homeira Vafaei, ${ }^{2}$ and Maryam Kasraeian ${ }^{2}$ \\ ${ }^{1}$ Imaging Research Center, Shiraz University of Medical Sciences, Shiraz, IR Iran \\ ${ }^{2}$ Department of Obstetrics and Gynecology, Shiraz University of Medical Sciences, Shiraz, IR Iran \\ "Corresponding author: Sakineh Dehghani, Imaging Research Center, Shiraz University of Medical Sciences, Shiraz, IR Iran. Tel: +98-9171076240, Fax: +98-7136474329, E-mail: \\ dehghanis90@gmail.com
}

Received 2015 November 20; Revised 2016 February 18; Accepted 2016 March 12.

\begin{abstract}
Background: Magnetic resonance imaging(MRI) is gradually becoming more common for thorough visualization of the fetus than ultrasound (US), especially for neurological anomalies, which are the most common indications for fetal MRI and are a matter of concern for both families and society.

Objectives: We investigated fetal MRIs carried out in our center for frequency of central nervous system anomalies. This is the first such report in southern Iran.

Materials and Methods: One hundred and seven (107) pregnant women with suspicious fetal anomalies in prenatal ultrasound entered a cross-sectional retrospective study from 2011 to 2013. A 1.5 T Siemens Avanto scanner was employed for sequences, including T2 HASTE and Trufisp images in axial, coronal, and sagittal planes to mother's body, T2 HASTE and Trufisp relative to the specific fetal body part being evaluated, and T1 flash images in at least one plane based on clinical indication. We investigated any abnormality in the central nervous system and performed descriptive analysis to achieve index of frequency.

Results: Mean gestational age \pm standard deviation(SD) for fetuses was $25.54 \pm 5.22$ weeks, and mean maternal age \pm SD was 28.38 \pm 5.80 years Eighty out of 107 (74.7\%) patients who were referred with initial impression of borderline ventriculomegaly. A total of 18 out of $107(16.82 \%)$ patients were found to have fetuses with CNS anomalies and the remainder were neurologically normal. Detected anomalies were as follow: 3 (16.6\%) fetuses each had the Dandy-Walker variant and Arnold-Chiari II (with myelomeningocele). Complete agenesis of corpus callosum, partial agenesis of corpus callosum, and aqueductal stenosis were each seen in 2 (11.1\%) fetuses. Arnold-Chiari II without myelomeningocele, anterior spina bifida associated with neurenteric cyst, arachnoid cyst, lissencephaly, and isolated enlarged cisterna magna each presented in one (5.5\%) fetus. One fetus had concomitant schizencephaly and complete agenesis of the corpus callosum.

Conclusions: MRI is superior to ultrasound and physical exam of live births in detection of CNS anomalies. In this investigation within a single referral center in southern Iran, anomalies included Dandy-Walker variant and Arnold-Chiari II as the most common findings. Other findings with lower incidence were complete and partial agenesis of corpus callosum, aqueductal stenosis, anterior spina bifida, schizencephaly, arachnoid cyst, lissencephaly, and isolated enlarged cisterna magna.
\end{abstract}

Keywords: Fetus, MRI, CNS Anomalies

\section{Background}

Though not the most common type of congenital anomaly, central nervous system (CNS) anomalies represent a major social and economic issue and can significantly impact the life quality of the affected individual and family. As CNS anomalies are usually compatible with life, prolonged hospitalization, higher health care costs, and uncertain future life quality are a significant burden to families and society, particularly in developing countries, where higher incidence of congenital anomalies is also encountered $(1,2)$.

Variable incidence rates have been reported for congenital CNS anomalies in studies from different parts of the world $(3,4)$. This variability has been attributed to ethnic variability and environmental factors. In Iran, sporadic reports of type and prevalence of congenital anomalies have been published. These studies have been performed on either live births (5-7) or using ultrasound (US) $(8,9)$. Magnetic resonance imaging (MRI) has not been used to our knowledge. The anomalies detected using MRI appear to represent a different spectrum. This variability is caused both by the difference in gestational age at time of surveillance, with nonviable fetuses dropping out in later live birth studies, and by the selective nature of MRI as a referral and problem-solving tool. Also, the anomalies reported in second trimester ultrasound are expected to differ from those found by MRI based on the different referral process 
for MRI.

Utilization of MRI as a problem-solving tool in prenatal diagnosis is rapidly expanding, both quantitatively in number of indications and qualitatively with the advent of cheaper, more rapid conventional MR images and new techniques. MRI is frequently used to investigate underlying etiologies of CNS anomalies that are not as readily detected by US. MRI provides good depictions of cortical malformations, anomalies of the corpus callosum, posterior fossa, and spinal column abnormalities. It can also confirm the presence of ventriculomegaly or additional associated abnormalities not detected by US. Through accurate identification of the fetal disorder, prenatal MRI can play a role in determination of pregnancy prognosis and in management (10). Because MRI is primarily used during the second and third trimesters and then only as a problem-solving tool, the spectrum of anomalies detected using MRI is not similar to those detected using either ultrasound or detected postnatally in live births.

\section{Objectives}

We present the spectrum of fetal CNS anomalies in found in the specific population referred for MRI in southern Iran.

\section{Materials and Methods}

From September 2011 to December 2013, pregnant women with suspected fetal anomalies diagnosed via prenatal ultrasound who were referred to Faghihi MRI center in Shiraz for fetal MRI were included in the research, which was designed as a cross-sectional retrospective study. MRI was performed on mothers within one to two weeks of referral. Those with fetal images showing other organ anomalies were excluded if no CNS anomaly was detected by MRI. A 1.5 T Siemens Avanto scanner with a 4-channel body coil was used for all MRIs. In fetal gestation age (GA) of $\geq 20$ weeks, mothers were examined in the right tilt position. Sequences including T2 HASTE and Trufisp images were obtained with 6-mm-thick slices in axial, coronal, and sagittal planes to the mother's body. T2 HASTE and Trufisp were done relative to the specific fetal body part being evaluated using images with a slice thickness of $4 \mathrm{~mm}$. T1 flash images were used in at least one plane based on clinical indication. A single radiologist, an assistant professor of radiology especially interested in fetal imaging, investigated the existing images for possible abnormality in the central nervous system.

All patients attended follow-up appointments with their physicians except those with diagnosis of DandyWalker variant, arachnoid cyst, and isolated cisterna magna; we thus confirmed the accuracy of our reports based on final clinical diagnosis. After delivery, MRI was also used to confirm the diagnosis when requested by the neonatologists.

The data were collected and descriptive analysis was done using SPSS version 6 (SPSS, Chicago, IL) to achieve index of frequency. Quantitative values are represented as mean \pm standard deviation (SD).

\section{Results}

During the study period, 107 pregnant females underwent MRI. Mean gestational age \pm SD for fetuses was 25.54 \pm 5.22 weeks, and mean maternal age \pm SD was $28.38 \pm 5$ years.

Most of patients (80 out of $107 ; 74.7 \%$ ) were referred with initial impression of borderline ventriculomegaly detected via US. A total of 18 patients out of 107 (16.82\%) were found to have fetal CNS anomalies; others were neurologically normal. Detected anomalies were as follow: 3 fetuses (16.6\%) each had Dandy-Walker variant and Arnold-Chiari II. Two fetuses (11.1\%) were diagnosed with complete agenesis of corpus callosum, two with partial agenesis of corpus callosum, and two with aqueductal stenosis. Arachnoid cyst, lissencephaly, anterior spina bifida, and isolated enlarged cisterna magna presented in one fetus each (5.5\%). One fetus was diagnosed with concomitant schizencephaly and complete agenesis of the corpus callosum. Detected anomalies are listed in Table 1.

\section{Discussion}

Fetal well-being is a matter of concern for both physicians and mothers. Ultrasonography has long been used as the first mode of fetal examination in clinical practice. It is widely available and gives the benefit of evaluating fetal and placental blood flow as well as offering reliable information about fetal development. However, in cases of oligohydramnios, maternal obesity, ossified skull, acoustic shadow in late pregnancy, and inconclusive results, US warrants a complementary examination to collect further information (10-21).

Magnetic resonance imaging emerged as a modality of fetal assessment in 1983. Its inherent advantages, including superior soft tissue contrast resolution, large field of view, lack of ionizing radiation, multiplanar imaging, and lack of dependency upon the operator, have encouraged the use of MRI as a problem-solving tool in detecting fetal anomalies revealed by US, particularly anomalies related to the central nervous system. MRI is also used to identify possible anomalies in conditions where the US results appear quite normal. These include complications 
Table 1. Prevalence of Fetal Central Nervous System Anomalies Detected by MRI During a Two-Year Surveillance Period in a Referral Center in Southern Iran

\begin{tabular}{lc}
\hline Disease & No. (\%) \\
\hline Dandy-Walker variant & $3 / 18(16.6)$ \\
\hline Arnold-Chiari II with myelomeningocele & $3 / 18(16.6)$ \\
\hline Partial agenesis of corpus callosum & $2 / 18(11.1)$ \\
\hline Aqueductal stenosis & $2 / 18(11.1)$ \\
\hline Complete agenesis of corpus callosum & $2 / 18(11.1)$ \\
\hline Complete agenesis of corpus callosum + schizencephaly & $1 / 18(5.5)$ \\
\hline Arnold-Chiari II without myelomeningocele & $1 / 18(5.5)$ \\
\hline Anterior spina bifida+ neurenteric cyst & $1 / 18(5.5)$ \\
\hline Arachnoid cyst & $1 / 18(5.5)$ \\
\hline Lissencephaly & $1 / 18(5.5)$ \\
\hline Isolated enlarged cisterna magna & $1 / 18(5.5)$ \\
\hline
\end{tabular}

of monochorionic twin pregnancies and history of central nervous system anomaly in a previous child of the same parents. Recent advances in in-utero fetal surgery and medical treatment have also contributed to the increasing use of MRI to gain additional information before surgical planning (22-28).

The guidelines set forward by the American college of radiology for MR imaging practices in 2013 sanctions performance of fetal MRI at any trimester if the benefits outweigh the probable risks for the mother and the fetus (9). This is based on the fact that to date no known harmful effects have been reported on fetuses undergoing MRI (10, $11,18,24,27,29)$. However, as small fetal size and excessive motion in the first trimester present limitations to performing the study, MRI is usually postponed until 20 weeks of gestation. Heat and acoustic hazards have also been proposed as possible disadvantages of MRI in the first trimester, but these have not been proven clinically important $(18,24)$. Contrast agents are considered group C during pregnancy and therefore should be avoided. The pregnant women should sign a written informed consent before the procedure $(10,11,27,29)$.

Different fast MRI sequences have been used to overcome fetal movement and reduce motion artifacts. The most popular fast T2-weighted sequences, which we followed as well, are half-Fourier acquired single-shot turbo spin-echo (HASTE) or single-shot fast spin-echo (SSFSE) sequences. Fast T1-weighted images such as the fast multiplanar gradient-recalled echo technique, which is not routinely used in our center, are less informative than T2weighted images; however, they can be useful in detecting hemorrhage, fat, or calcification $(10,28,29)$. Gradientecho echo-planar T2-weighted images can also be utilized for better detection of intracranial hemorrhage (10, 28). Diffusion-weighted imaging and MR spectroscopy are advanced techniques that may help to better distinguish developmental or destructive pathologies $(10,27-29)$.

Among the reasons to refer patients for fetal MRI, central nervous system (CNS) abnormalities ranked first (16.82\%) in this study, as previously mentioned. This is obviously higher than the percentages reported in Rafsanjan (3.35\%) and in Ahvaz (11.7\%) $(6,7)$. This can be attributed to different sources of reports, prenatally with MRI versus clinical exam after birth. Here we are also able to report different CNS malformations separately, which can influence the management of the fetus; this is not achievable with postnatal exam as performed in those studies.

Ventriculomegaly is the leading suspected CNS problem prompting physicians to perform MRI (18, 27, 30-33). Consistent with other studies, about $74.7 \%$ of our patients were primarily diagnosed with ventriculomegaly via US. It is diagnosed when the atria of the lateral ventricle measures more than $10 \mathrm{~mm}$. Disagreements may arise between different observers regarding the measured size of ventricles; MRI has a problem-solving role in this regard, particularly when three-dimensional (3D) volumetric methods are employed $(23,29)$. Many cases of ventriculomegaly referred to us were mild cases. Our results are concordant with the literature; isolated mild ventriculomegaly (10 $12 \mathrm{~mm}$ ) usually, though not invariably, results in normal pregnancy outcome and is sometimes considered a normal variant (30). Also, because this is a new modality and there are limitations in patient acceptance, many ultrasonographers will not even refer the mother if they can find a gross anomaly and give the mother a final conclusion. Most will only refer the patient if they detect the find- 
ing only as an isolated finding. There is thus an inherent selection bias in the MRI population.

Along with confirming the diagnosis, it is important to investigate the patient with MRI to seek concomitant findings that may influence fetal outcome $(17,18,30,31)$. In fact, ventriculomegaly can be an associated finding in a variety of CNS anomalies that are not amenable to ultrasonographic detection, such as cortical malformations, heterotopias, schizencephaly, posterior fossa abnormalities, agenesis of corpus callosum, neural tube defects, and intraventricular hemorrhage (29). In this study, 2 out of 18 patients (11.1\%) were found to have aqueductal stenosis as the cause of non-communicating hydrocephalus (Figure 1). Aqueductal stenosis was significantly more prevalent in north-west Iran (23\%) in a study based on US (9).

The corpus callosum (CC) can be better delineated by MRI than by US. Agenesis of the corpus callosum is estimated to occur in approximately $0.2 \%-0.7 \%$ of the general population. Isolated callosal anomalies are detected most directly in the sagittal and coronal MRI planes. Associated anomalies are also more easily detected via MRI as compared to US $(10,22,34)$. Along with direct non-visualization of the CC, there are indirect signs that indicate possible callosal agenesis and prompt further evaluation of the fetal brain. Absent cavum septum pellucidum $(28,35,36)$, straight and parallel lateral ventricles, dilated occipital horn of lateral ventricles (colpocephaly) and high-riding third ventricle $(17,27)$ are indirect signs that are mostly reported and more easily demonstrated in US examination. Complete agenesis of CC was one of the common MRI findings in this study (11.1\%) (Figures 2 and 3); in addition, the corpus callosum did not develop completely in its splenium segment (partial agenesis) in $11.1 \%$ of our patients, in whom we did not witness indirect signs. Complete agenesis was much less common (2\%) in Ghavami et al.'s investigation (9).

Early in pregnancy, cerebral parenchyma exhibits a smooth surface and ventricles are relatively large. When the fetus matures, the sulci appear (27). Precise timing of each sulcus is available on atlases, which are used for proper interpretation of fetal brain development (12, 27, 37). An abnormal sulcation pattern may be recognized as numerous sulci that are not expected for a less mature fetus (polymicrogyria) or extremely few sulci(lissencephaly) and cleavage in gray matter extending from the ventricular margin to the brain surface (schizencephaly) in a more mature fetus. In this study, two fetuses had abnormal sulcation. One (5.5\%) of them was found to have schizencephaly along with complete agenesis of the CC (Figure $3)$. Schizencephaly is similarly uncommon (1\%) in northwest Iran (9). Lissencephaly was also confirmed by MRI in the fetus of one of the patients who had a positive his- tory of lissencephaly in her previous gestation, which in that case led to the infant's death soon after delivery. Other parenchymal abnormalities such as heterotopias, hemorrhage, gliosis, and white matter edema, although not reported here, can be clearly depicted owing to the high contrast resolution of MRI $(11,15,20,27,28)$.

Assessment of posterior fossa is difficult by US and it becomes even more challenging when the skull begins to ossify. MRI plays an important role in this regard. Prenatal MRI can evaluate posterior fossa abnormalities quite well, including Dandy-Walker syndrome, Dandy-Walker variant, mega cisterna magna, arachnoid cyst, and Chiari malformation type II $(17,22,23,28)$. We did not see DandyWalker syndrome, but isolated mega cisterna magna and quadrigeminal arachnoid cyst were each seen in one case (5.5\%). Ghavami et al. reported a rate of $2 \%$ for arachnoid cysts in their US-based study (9). However, DandyWalker variant (Figure 4) and Chiari malformation type II were the two most common neurological findings in this study (each occurring in $16.6 \%$ of cases). Ghavami et al. also noted Chiari malformation as the most common (37\%) anomaly in their report, while Dandy-Walker was found to have a low (4\%) rate of presentation (9). Interestingly, one of the fetuses with Chiari malformation type II (Figure 5) underwent intrauterine fetal surgery for accompanying lumbar myelomeningocele. Although there was agreement between US and MRI on the presence of a neural tube defect, MRI had a remarkable role in this regard based on its precise description of the defect and related findings before operation.

Normal measurements of cerebellum, vermis, and cisterna magna are now available for interpretation and differentiation of disease entities. When cisterna magna, a key structure in prenatal US examination, is larger than 10 $\mathrm{mm}$, mega cisterna magna is established. This may be an isolated finding; however, US may not detect vermian hypoplasia and may misinterpret it as isolated mega cisterna magna (22). Small posterior fossa, on the other hand, may lead to crowding and herniation of its components, giving rise to Chiari symptoms (16). MRI is needed to evaluate the presence and configuration of cerebellar and midbrain structures in detail to confirm specific syndromes and their associated findings (25), as it gave us complete assurance about one case of isolated mega cisterna magna.

Neural tube defects are adequately diagnosed by US. MRI has a complementary role in the detection of concomitant posterior fossa abnormalities (Chiari type II) and the extent and contents of the herniated sac or malformations hidden in US such as diastematomyelia $(10,11,27)$. Myelomeningocele was demonstrated in three (16.6\%) of our patients, accompanying Chiari II malformation in all of them (Figure 5B). Lower incidence of myelomeningocele 

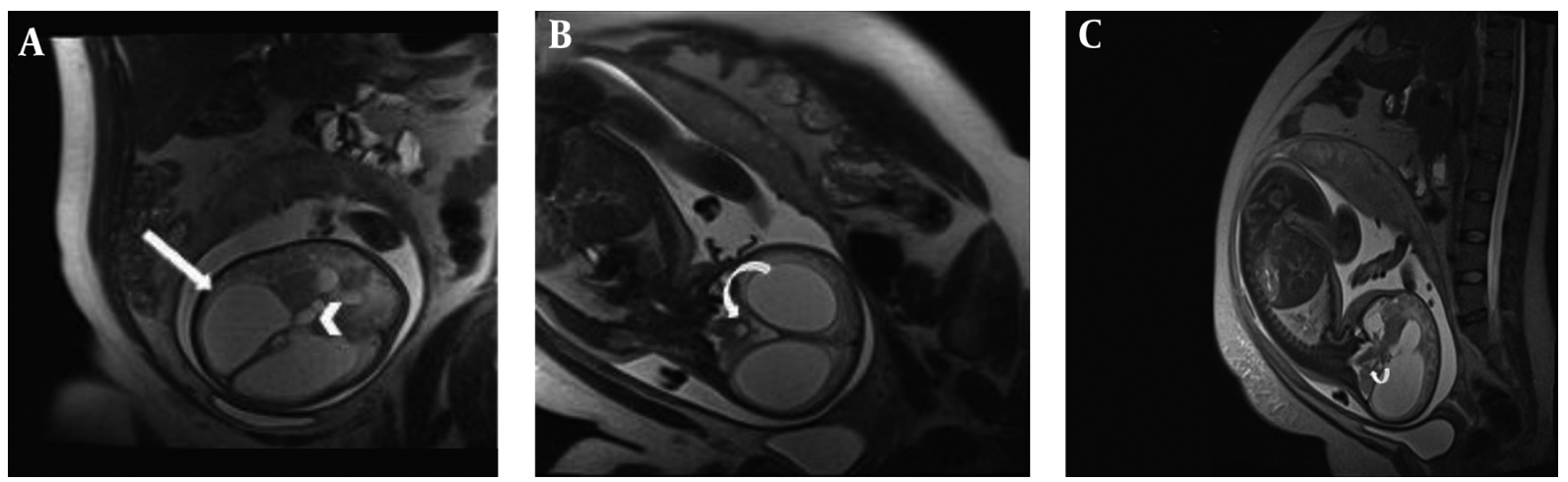

Figure 1. Aqueductal stenosis in a fetus with 28 weeks gestational age (wks GA). Axial(A), coronal(B) and sagittal(C)T2 HASTE image of fetal brain showing significant dilatation of lateral ventricle(arrow) and third ventricle(arrow head). Normal diameter of fourth ventricle (curved arrow) is the clue to diagnosis of aqueductal stenosis.

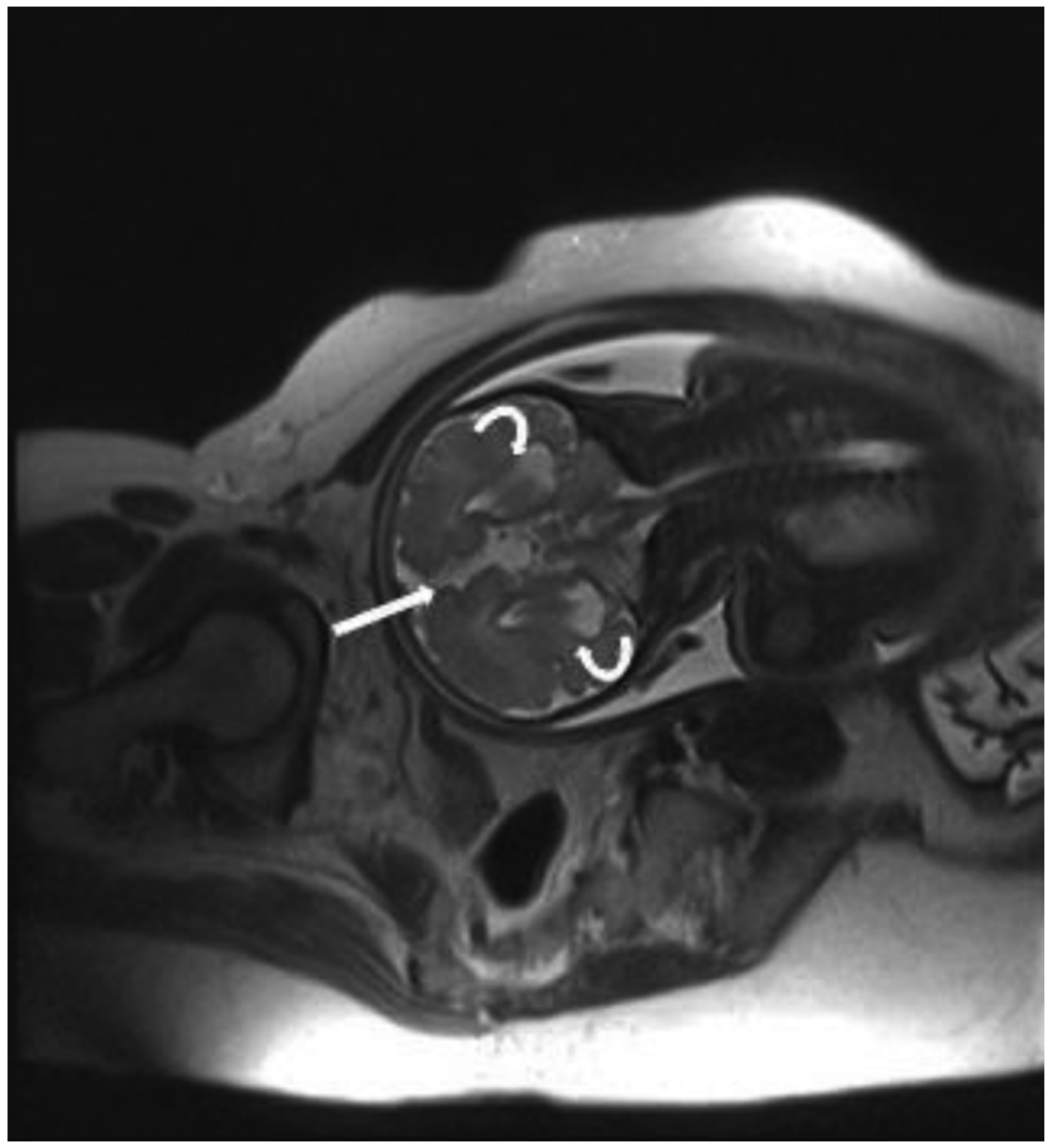

Figure 2. Complete agenesis of corpus callosum in a fetus with 35 wks GA. Coronal T2 HASTE image shows no fusion between two cerebral hemispheres and absence of corpus callosum(straight arrow) as direct signs and parallel alignment of lateral ventricles resembling "Tear Drop" (curved arrows)as an indirect sign of complete agenesis of corpus callosum. 

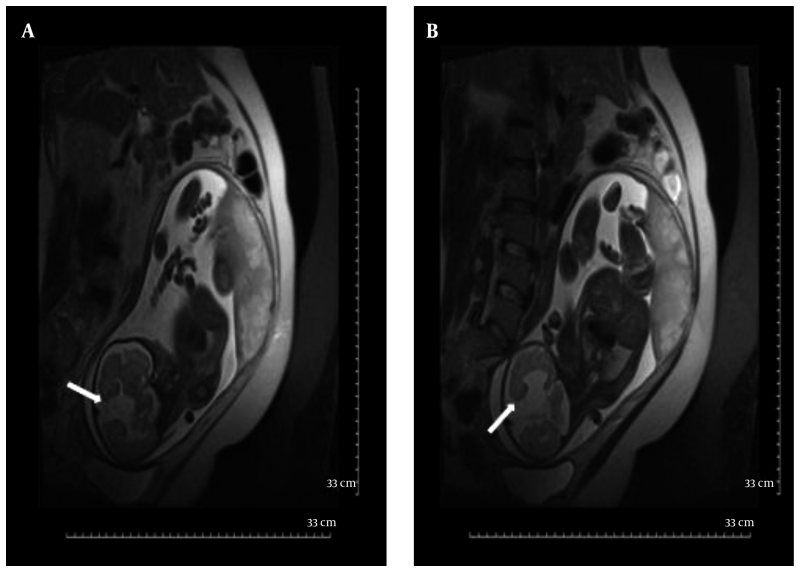

Figure 3. A and B, Schizencephaly in a fetus with 34wks GA. Coronal T2 HASTE images show Cleavage in gray matter extending from ventricular margin to brain surface in two different sections (arrows). Both side of cleavage are covered by hypo-intense thin cortex. Abnormal fusion of midline structures and complete agenesis of corpus callosum is also present.
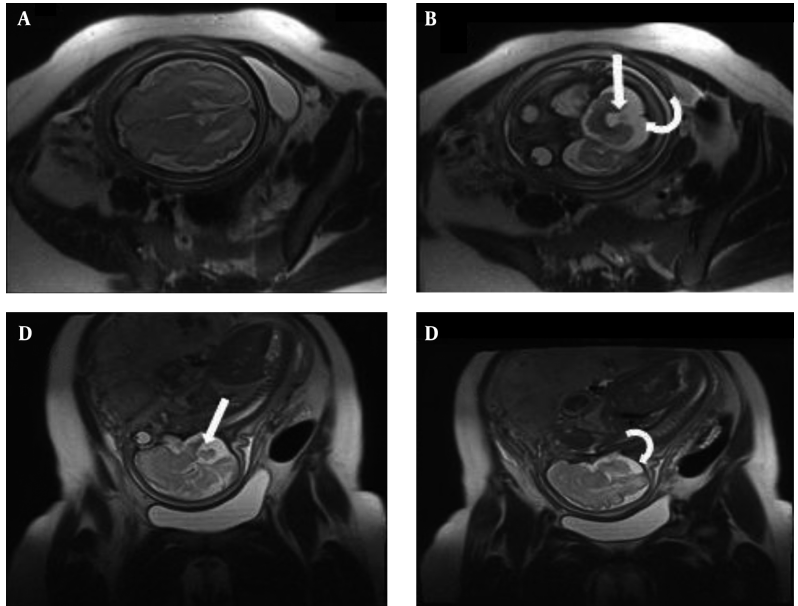

Figure 4. Dandy-Walker variant in a fetus with 27wks GA. Axial(A and B) and sagittal(C and D) T2 HASTE images show hypoplastic lower vermis (arrows) and enlarged cisterna magna (curved arrows) and otherwise normal brain parenchyma.

was reported by Kazmi et al. (12.5\%) in a study in northern Iran using ultrasound (8).Tethered cord could be easily noticed in all the fetuses who had some degree of neural tube defect in the spine. We also detected one case of neurenteric cyst and associated anterior spina bifida without any other detectable anomaly.

Anencephaly (16\%) and encephalocele ( $8 \%$ ), which were reported by Ghavami et al. (9), were not detected in this study because their study was based on ultrasound in the first trimester, while MRI is performed in the second and third trimester when fetuses with these major anomalies have already been aborted.

Magnetic resonance imaging has also been used to evaluate morbidities associated with impaired brain per- fusion in the case of shared placenta in monochorionic twins $(10,27)$. Insults endangering the surviving twin after the demise of the co-twin and serious complications of twin-twin transfusion syndrome are not easily detectable via US $(10,11)$. Diffusion-weighted MRI has also improved diagnosis of ischemic events (11). We saw two twin pregnancies in this study that were referred for suspected nonneurological findings. Although they both had monochorionic placentation, no sign of brain ischemic events was established.

\subsection{Conclusions}

Based on our first two years of experience with fetal MRI in a single referral center in southern Iran, MRI 

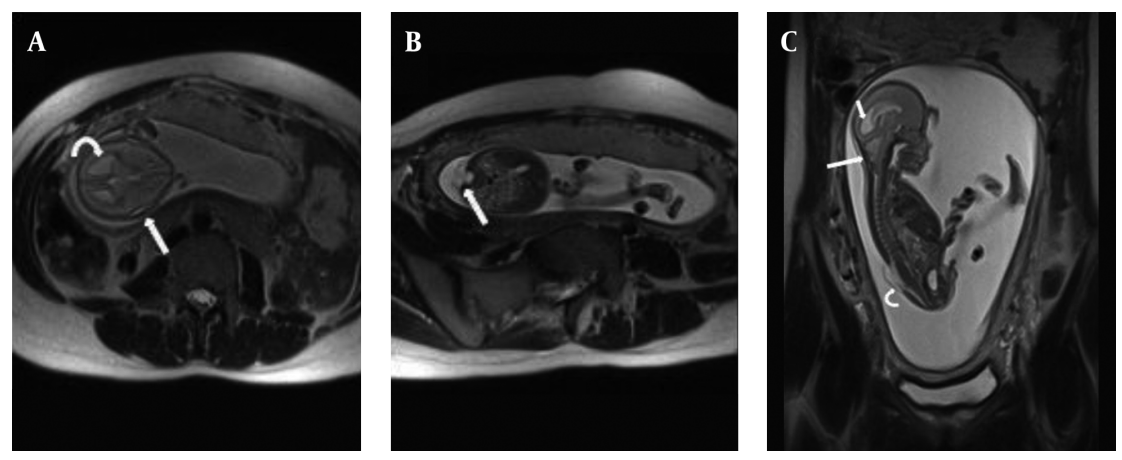

Figure 5. Arnold Chiari II in a fetus at 20wks GA; (A) Axial T2 HASTE image of fetal brain shows a "lemon Shape" skull(straight arrow) and dilatation of posterior horns of lateral ventricles (curved arrow). (B) axial T2 HASTE image of lumbar spine; open neural tube defect with associated myelomeningocele(straight arrow). (C) Sagittal T2 HASTE image of entire fetal body shows combination of findings; small crowded posterior fossa, herniation of inferior vermis and fourth ventricle(large arrow), dilatation of lateral ventricles(small arrow) and myelomeningocele in lumosacral spine(curved arrow).

findings for congenital anomalies included the following: Dandy-Walker variant, Arnold-Chiari II, complete and partial agenesis of the corpus callosum, aqueductal stenosis, anterior spina bifida, schizencephaly, arachnoid cyst, lissencephaly, and isolated enlarged cisterna magna in decreasing order. These frequencies are different in comparison to studies reporting CNS anomalies using ultrasound or live births.

A preliminary abstract of this article was presented orally in the 30th Iranian congress of radiology on May 13th, 2014.

\section{Acknowledgments}

The authors thank the MRI technicians of Faghihi hospital for technical assistance.

\section{Footnotes}

Authors' contribution Sepideh Sefidbakht, conception and design, acquisition of data, analysis and interpretation of data, drafting the article, critical revision of the article, final approval of the version to be published; Sakineh Dehghani* (corresponding author ), conception and design, acquisition of data, analysis and interpretation of data, drafting the article, critical revision of the article, final approval of the version to be published; Maryam Safari, conception and design, acquisition of data; Homeira Vafaei, conception and design.

Financial disclosure Authors have no conflict of interest to disclose.

\section{References}

1. Mohammed AR, Mohammed SA, AbdulFatah AM. congenital anomalies among children: Knowledge and attitude of Egyptian and Saudi Mothers. Biol Agr Healthcare. 2013;3:2224-3208.
2. Joel-Medewase VI, Adeleye AO. The social-economic and family background of the child with a CNS birth defect in a developing country in the current era. Nigerian J Paediatr. 2014;42(1):55-8.

3. Karim R, Wahab S, Akhtar R, Jamala F, Jabeen S. Frequency and pattern of distribution of antenatally diagnosed congenital anomalies and the associated risk factors. J Postgraduate Med Inst. 2014;28(2).

4. Jadav SHR. Study of congenital malformations in Central nervous system and gastrointestinal Tract. Nat J Med Res. 2012;2(2):121-3.

5. Sarrafan N, Mahdinasab SAH, Arastoo L. Incidence of congenital malformations of extremities in live-born neonates in Ahvaz. Sci Med J Jondishapoor. 2011;10(1):13-9.

6. Masoodpoor N, Arab-Baniasad F, Jafari A. Prevalence and pattern of congenital malformations in newborn in Rafsanjan, Iran (2007-08). J Gorgan Univ Med Sci. 2013;15(3).

7. Ahmadzadeh A, Safikhani Z, Abdulahi M, Ahmadzadeh A. Congenital malformations among live births at Arvand Hospital, Ahwaz, Iran-A prospective study. PakJ Med Sci. 2008;24(1):33.

8. Kazmi SS, Nejat F, Tajik P, Roozbeh H. The prenatal ultrasonographic detection of myelomeningocele in patients referred to Children's Hospital Medical Center: a cross sectional study. Reprod Health. 2006;3:6. doi: 10.1186/1742-4755-3-6. [PubMed: 16846520].

9. Ghavami M, Abedinzadeh R. Prevalence of perinatal central nervous system anomalies in East azarbaijan-iran. Iran J Radiol. 2011;8(2):79-81. [PubMed: 23329921].

10. Glenn OA, Coakley FV. MRI of the fetal central nervous system and body. Clin Perinatol. 2009;36(2):273-300. doi: 10.1016/j.clp.2009.03.016. [PubMed: 19559321] viii.

11. Kosus A, Kosus N, Usluogullari B, Duran M, Turhan NO, Teksam M. Fetal magnetic resonance imaging in obstetric practice.J Turk Ger Gynecol Assoc. 2011;12(1):39-46. doi: 10.5152/jtgga.2011.09. [PubMed: 24591956].

12. Kosla K, Majos M, Polguj M, Antosik-Biernacka A, Stefanczyk L, Majos A. Prenatal diagnosis of a vein of Galen aneurysmal malformation with MR imaging - report of two cases. Pol J Radiol. 2013;78(4):88-92. doi: 10.12659/PJR.889613. [PubMed: 24505230].

13. Zhan J, Dinov ID, Li J, Zhang Z, Hobel S, Shi Y, et al. Spatialtemporal atlas of human fetal brain development during the early second trimester. Neuroimage. 2013;82:115-26. doi: 10.1016/j.neuroimage.2013.05.063. [PubMed: 23727529].

14. Kuklisova-Murgasova M, Cifor A, Napolitano R, Papageorghiou A, Quaghebeur G, Rutherford MA, et al. Registration of 3D fetal neurosonography and MRI. Med Image Anal. 2013;17(8):1137-50. doi: 10.1016/j.media.2013.07.004. [PubMed: 23969169]. 
15. Manganaro L, Saldari M, Bernardo S, Aliberti C, Silvestri E. Bilateral subependymal heterotopia, ventriculomegaly and cerebellar asymmetry: fetal MRI findings of a rare association of brain anomalies. $J$ Radiol Case Rep. 2013;7(11):38-45. doi: 10.3941/jrcr.v7i11.1457. [PubMed: 24421929].

16. Liu F, Zhang Z, Lin X, Teng G, Meng H, Yu T, et al. Development of the human fetal cerebellum in the second trimester: a post mortem magnetic resonance imaging evaluation. J Anat. 2011;219(5):582-8. doi: 10.1111/j.1469-7580.2011.01418.x. [PubMed: 21812776].

17. Wang GB, Shan RQ, Ma YX, Shi H, Chen LG, Liu W, et al. Fetal central nervous system anomalies: comparison of magnetic resonance imaging and ultrasonography for diagnosis. Chin Med J (Engl). 2006;119(15):1272-7. [PubMed: 16919186].

18. Coakley FV, Glenn OA, Qayyum A, Barkovich AJ, Goldstein R, Filly RA. Fetal MRI: a developing technique for the developing patient. AJR Am J Roentgenol. 2004;182(1):243-52. doi: 10.2214/ajr.182.1.1820243. [PubMed: 14684546].

19. Griffiths PD, Porteous M, Mason G, Russell S, Morris J, Fanou EM, et al. The use of in utero MRI to supplement ultrasound in the foetus at high risk of developmental brain or spine abnormality. $\mathrm{Br} J$ Radiol. 2012;85(1019):e1038-45. doi: 10.1259/bjr/23696508. [PubMed: 22763035].

20. Glenn OA, Cuneo AA, Barkovich AJ, Hashemi Z, Bartha AI, Xu D. Malformations of cortical development: diagnostic accuracy of fetal MR imaging. Radiology. 2012;263(3):843-55. doi: 10.1148/radiol.12102492. [PubMed: 22495681].

21. Hosseinzadeh K, Luo J, Borhani A, Hill L. Non-visualisation of cavum septi pellucidi: implication in prenatal diagnosis?. Insights Imaging. 2013;4(3):357-67. doi: 10.1007/s13244-013-0244-x. [PubMed: 23584847].

22. Glenn OA, Barkovich J. Magnetic resonance imaging of the fetal brain and spine: an increasingly important tool in prenatal diagnosis: part 2. AJNR Am J Neuroradiol. 2006;27(9):1807-14. [PubMed: 17032846].

23. Simon EM, Goldstein RB, Coakley FV, Filly RA, Broderick KC, Musci TJ, et al. Fast MR imaging of fetal CNS anomalies in utero. AJNR Am J Neuroradiol. 2000;21(9):1688-98. [PubMed: 11039352].

24. Wieseler KM, Bhargava P, Kanal KM, Vaidya S, Stewart BK, Dighe MK. Imaging in pregnant patients: examination appropriateness. $R a$ diographics. 2010;30(5):1215-29. doi: 10.1148/rg.305105034. [PubMed: 20833847] discussion 1230-3.

25. Poutamo J, Vanninen R, Partanen K, Ryynanen , Kirkinen P. Magnetic resonance imaging supplements ultrasonographic imaging of the posterior fossa, pharynx and neck in malformed fetuses. Ultrasound Obstet Gynecol. 1999;13(5):327-34. doi: 10.1046/j.14690705.1999.13050327.x. [PubMed: 10380297].

26. Griffiths PD, Russell SA, Mason G, Morris J, Fanou E, Reeves MJ. The use of in utero MR imaging to delineate developmental brain abnormalities in multifetal pregnancies. AJNR Am J Neuroradiol. 2012;33(2):35965. doi: 10.3174/ajnr.A2762. [PubMed: 22095964].

27. Saleem SN. Fetal MRI: An approach to practice: A review. J Adv Res. 2014;5(5):507-23. doi: 10.1016/j.jare.2013.06.001. [PubMed: 25685519].

28. Glenn OA. MRimaging of the fetal brain. Pediatr Radiol. 2010;40(1):6881. doi: 10.1007/s00247-009-1459-3. [PubMed: 19937234].

29. Glenn OA, Barkovich AJ. Magnetic resonance imaging of the fetal brain and spine: an increasingly important tool in prenatal diag nosis, part 1. AJNR Am J Neuroradiol. 2006;27(8):1604-11. [PubMed: 16971596].

30. Beeghly M, Ware J, Soul J, du Plessis A, Khwaja O, Senapati GM, et al. Neurodevelopmental outcome of fetuses referred for ventriculomegaly. Ultrasound Obstet Gynecol. 2010;35(4):405-16. doi: 10.1002/uog.7554. [PubMed: 20069560].

31. Lyall AE, Woolson S, Wolfe HM, Goldman BD, Reznick JS, Hamer RM, et al. Prenatal isolated mild ventriculomegaly is associated with persistent ventricle enlargement at ages 1 and 2. Early Hum Dev. 2012;88(8):691-8. doi: 10.1016/j.earlhumdev.2012.02.003. [PubMed: 22445211].

32. Li Y, Estroff JA, Mehta TS, Robertson RL, Robson CD, Poussaint TY, et al. Ultrasound and MRI of fetuses with ventriculomegaly: can cortical development be used to predict postnatal outcome?. AJR Am J Roentgenol. 2011;196(6):1457-67. doi: 10.2214/AJR.10.5422. [PubMed: 21606314].

33. Santo S, D'Antonio F, Homfray T, Rich P, Pilu G, Bhide A, et al. Counseling in fetal medicine: agenesis of the corpus callosum. Ultrasound Obstet Gynecol. 2012;40(5):513-21. doi: 10.1002/uog.12315. [PubMed: 23024003].

34. Malinger G, Lev D, Oren M, Lerman-Sagie T. Non-visualization of the cavum septi pellucidi is not synonymous with agenesis of the corpus callosum. Ultrasound Obstet Gynecol. 2012;40(2):165-70. doi: 10.1002/uog.11206. [PubMed: 22689012].

35. Li Y, Sansgiri RK, Estroff JA, Mehta TS, Poussaint TY, Robertson RL, et al Outcome of fetuses with cerebral ventriculomegaly and septum pellucidum leaflet abnormalities. AJR Am J Roentgenol. 2011;196(1):W8392. doi: 10.2214/AJR.10.4434. [PubMed: 21178039].

36. Zhang Z, Hou Z, Lin X, Teng G, Meng H, Zang F, et al. Development of the fetal cerebral cortex in the second trimester: assessment with 7T postmortem MR imaging. AJNR Am J Neuroradiol. 2013;34(7):1462-7. doi: 10.3174/ajnr.A3406. [PubMed: 23413246].

37. Tarui T, Khwaja OS, Estroff JA, Robinson JN, Gregas MC, Grant PE. Altered fetal cerebral and cerebellar development in twin-twin transfusion syndrome. AJNR Am J Neuroradiol. 2012;33(6):1121-6. doi: 10.3174/ajnr.A2922. [PubMed: 22300937]. 